\title{
SUSPENSION-TO-SUSPENSION JUSTIFICATION PRINCIPLES
}

\begin{abstract}
We will be in a better position to evaluate some important skeptical theses if we first investigate two questions about justified suspended judgment. One question is this: when, if ever, does one justified suspension confer justification on another suspension? And the other is this: what is the structure of justified suspension? The goal of this essay is to make headway at answering these questions. After surveying the four main views about the non-normative nature of suspended judgment and offering a taxonomy of the epistemic principles that might govern which suspended judgments are justified, I will isolate five important principles that might govern which suspended judgments are justified. I will call these suspension-to-suspension principles. I will then evaluate these principles by the lights of each of the four views about what suspensions are. I close by drawing some conclusions about the prospects for skepticism, the structure of justified suspended judgment, and the importance of theorizing about justified suspended judgment.
\end{abstract}

Keywords: coherentism, foundationalism, infinitism, skepticism, suspended judgment

While sophisticated theories of justified belief have proliferated, especially in the recent history of western epistemology, the same is not true for theories of justified suspended judgments (hereafter "suspensions"). This is unfortunate since it may mean that that we are not yet in a strong position to fully understand and evaluate various skeptical theses. The skeptical theses I have in mind are those that say that suspension is the only stance we are justified in taking to the claims in some domain. Fortunately, times are changing. Epistemologists have recently started to study suspension much more closely than they have before. ${ }^{1}$ This paper adds to this new trend by offering some new arguments that bear on the nature of justified suspension, and consequently on skepticism's prospects.

My focus will be on two questions that any adequate theory of justified suspension must answer. First, when, if ever, does one justified suspension

1 Due in large part to the groundbreaking work of Jane Friedman. See especially Friedman (2013) and (2017). For some interesting criticisms of some of Friedman's work, see Archer (2018) and Archer (forthcoming). 
confer justification on another suspension? And second, how do clusters of justified suspensions hang together? Possible answers to these questions consist in epistemic principles that might govern justified suspensions. ${ }^{2}$ After providing a taxonomy of the kinds of principles that might govern the realm of justified suspensions, I will argue that some of the key principles that might govern when one justified suspension confers justification on another suspension and some of the key principles that might govern how justified suspensions hang together should be rejected. I will then look at what these negative findings mean for the skeptic's prospects, the structure of justified suspension, and the importance of theorizing about justified suspension.

The paper has five main sections. Since the non-normative nature of suspension is an important determinant of the justification norms that govern suspensions, and since the non-normative nature of suspension is a matter of dispute, I will begin, in Section 1, by reviewing the main contending views about the nature of suspension. Rather than trying to decide among these views (something that would require a very different, and much longer, essay), I will proceed in a theory-neutral manner and look at how each of the contending views about the nature of suspension fits with various suspension principles. In Section 2, I step back and offer a taxonomy of the kinds of principles that might govern justified suspensions. Within that taxonomy, I locate what I will be calling suspension-to-suspension principles. These principles are modeled on the familiar Closure, Transmission, and CounterClosure principles that are sometimes thought to govern justified belief. In Section 3, I say why these principles are especially important for the theory of justified suspension. In Section 4, I determine how each of these principles fares on the theories identified in Section 1. Then in Section 5, I draw some lessons.

\section{Views About The Nature of Suspension}

Both of my main questions concern the normative nature of suspension. To answer these questions, though, we may first have to identify suspension's non-normative nature. So I will begin by briefly stating the main competing views about the non-normative nature of suspension. ${ }^{3}$ I am interested here in views with ontological ambitions - views, that is, that try to capture what

2 If there are no true epistemic principles that govern suspensions, then the correct theory of justified suspension might be a particularist one. My working assumption is that the epistemic status of particular suspensions is governed by general principles.

3 Epistemologists almost invariably theorize about the normative nature of belief without first taking a view about the ontology of belief. Below I provide reason to think that this same way of proceeding is not suitable for theorizing about the normative nature of suspension. 
suspensions are identical to, and not views which merely state necessary and sufficient conditions on someone's suspending judgment. With this in mind, here are the views ${ }^{4}$ :

The Sharp Credence View: to suspend about $p$ is to equally divide one's credence between $p$ and not- $p$ by having a 0.5 credence that $p$ and a 0.5 credence that not-p. ${ }^{5}$

The Maximally Mushy Credence View: to suspend about $p$ is to be in a maximally mushy credence state regarding $p$, where this state is spread out across the full $0-1$ interval. ${ }^{6}$

Higher-Order Belief Views: to suspend about $p$ is to have some distinctively epistemic higher-order belief - for example, the belief that one is neither justified in believing $p$ nor justified in disbelieving $p .^{7}$

The Inquiry View: to suspend about $p$ is to inquire into whether or not $p$ is true. ${ }^{8}$

Though much can be said in favor of, and against, each of these views about suspension's non-normative nature, my main concern will be with the epistemic norms that govern suspensions. Consequently, I am going to remain as neutral as possible about the (non-normative) nature of suspension. ${ }^{9}$ Still there are obvious connections between views about the (non-normative) nature of suspension and theories of justified suspension. After all, it seems that Proponents of The Sharp Credence View must take the epistemology of sharp credences as providing the correct theory of justified

4 I omit the view, now widely dismissed, which says that suspending regarding $p$ is identical to not believing $p$ and not believing not- $p$. This view has several problems, among them that we do not suspend about propositions that we never entertain. More generally, in offering these four candidate views of the nature of suspension, I assume that suspending is an attitude of some kind; for a defense of this assumption, see Friedman (2013a).

5 The Sharp Credence View is an example of a middling sharp credence view, where views of this kind say that to suspend about $p$ is to equally, or to approximately, divide one's credence between $p$ and not- $p$ by (i) having a 0.5 , or close to 0.5 , credence that $p$; and (ii) having a 0.5 , or close to 0.5 , credence that not-p. The points that I go on to make about The Sharp Credence View also apply to other middling credence views. For detailed discussion and criticism of middling sharp credence views, see Friedman (2013b).

6 For discussion and development of this view, see Sturgeon (2010). I borrow the term "mushy credence" from White (2010).

7 For discussion and development of this view, see Raleigh (forthcoming); Rosenkranz (2007) is also relevant.

8 See Friedman (2017), though Friedman is primarily interested in defending the view that suspension and inquiry are biconditionally related, and not the stronger view that they are identical.

9 If all four of the views I have outlined are mistaken, and some fifth view is correct, I hope to have at least uncovered a few things about the epistemology of the attitudes isolated in these four views. Of course, if one of those four views is correct, we will have learned about three other important kinds of attitudes as well. 
suspension; that proponents of The Maximally Mushy Credence View must take the epistemology of mushy credences as providing the correct theory of justified suspension; that proponents of Higher-Order Belief Views must take the theory of justified belief as providing the correct theory of justified suspension; and that proponents of The Inquiry View must take the epistemology of inquiry (which tells us when inquiring into some question is justified) as providing the correct theory of justified suspension. In the face of these diverse views about the nature and norms of suspension, I will remain neutral and try to argue from inductions across these four views about the nature of suspension and their accompanying theories of justified suspension. This will allow us to determine where there is, and where there is not, unanimity about whether some suspension principle is true. As we will see, there is some impressive unanimity. Before getting to the supporting inductions though, we need to survey the general principles that might govern the justification of suspensions.

\section{A Taxonomy of Candidate Suspension Principles}

My next task is to provide a taxonomy of the candidate principles that might govern whether some given suspension is justified. Note that I am after candidate principles. These are the principles that we need to consider when constructing a full theory of justified suspension. Though I will ultimately reject some of these principles, I need to begin by identifying and organizing all of the candidate suspension principles in a way that is helpful for understanding and evaluating those principles.

\subsection{Strong and Weak Suspension Principles}

The candidate principles divide into strong principles and weak principles. These two kinds of principles are closely connected to the two organizing questions that I mentioned at the outset. Recall that the first question was this: when, if ever, does one justified suspension confer justification on another suspension? Proposed answers to this question will cite strong principles. A strong principle is a generalization that tells us what confers justification on some justified suspensions. For example, a subset of strong principles consists in those principles that tell us when some justified suspensions confer justification on other suspensions. More generally though, any generalization which claims that some specified kind of fact confers justification on some specified suspensions counts as a strong principle. I refer to these as strong principles because they go beyond stating necessary or sufficient conditions for a suspension's being justified, and identify what it is that confers justification on suspensions. The notion of conferring is crucial to a principle being a strong principle. This notion is meant to be an ecumenical one that can cover a variety of ideologies. So you can think of it in terms of 
what metaphysically grounds the justification of the relevant suspensions, or you can think of it in terms of what the truth-makers are for ascriptions of justified suspensions, or you can think of it in terms of what it is in-virtue of which those suspensions are justified, etc.

Weak principles, by contrast, carry no implications about what confers justification on suspensions. Weak principles are less ambitious: they simply identify necessary, or sufficient, conditions for a suspension's being justified. Still weak principles are important because they tell us how justified suspensions hang together. This makes them crucial for determining the answer to my second organizing question. Recall that was this question: how do clusters of justified suspensions hang together? One justified suspension, as I will put it, hangs together with another suspension, as long as one necessitates, or suffices, for the other. However, since neither necessitating nor sufficing requires that one suspension confers justification on another suspension, these principles are logically weaker than strong principles.

The distinction between strong and weak principles has some important implications. Since a strong principle might be false, but only because what it cites does not confer justification on suspensions, though what it cites does suffice for that suspension to be justified, strong principles have weak counterpart principles that cite a sufficient condition for the relevant suspension to be justified. A corollary of this is that a strong principle entails the corresponding weak principle that cites a sufficient condition on the justification of some suspensions, while that weak principle does not entail that strong principle. It also follows that weak principles that cite a necessary condition on the justification of some suspensions do not have strong principles as counterparts. ${ }^{10}$

\subsection{A Taxonomy of Kinds of Suspension Principles}

To generate the candidate strong and weak principles that might govern justified suspensions, I am going to look to the familiar strong and weak principles that have been proposed for justified belief; I will transpose the principles that I find there to arrive at a set of principles that might govern justified suspensions.

In the arena of justified belief, strong principles can be distinguished by the kinds of items that are claimed to confer justification on some of our beliefs. Those candidate items are:

1. other justified beliefs,

2. other justified doxastic states of the subject (e.g. justified credences or justified suspensions),

3. non-doxastic states of the subject (e.g. perceptual experiences),

10 This is because the satisfaction of a necessary condition on the truth of $x$ is $f$ does not entail that $x$ is $f$ and so it does not entail that anything confers $f$ on $x$. 
4. the reliability of the belief-forming process (and methods) that produced the belief,

5. the indispensable role that the belief plays in some inquiry (as proponents of justified belief in hinge propositions contend),

6. a feature of the belief (or its context) that confers default justification on it,

7. a combination of the previous items.

Transposing this to the realm of justified suspensions yields candidate strong principles, which claim that the following items confer justification on some of our suspensions:

1. other justified suspensions,

2. other justified doxastic states of the subject (e.g. justified beliefs or justified credences),

3. non-doxastic states of the subject (e.g. perceptual experiences),

4. some property of the suspension-forming process (and methods) that produced the suspension,

5. the indispensable role that the suspension plays in some inquiry,

6. a feature of the suspension (or its context) that confers default justification,

7. a combination of the previous items.

This delivers the branch of the taxonomy that consists in the candidate strong principles.

To complete the taxonomy, we need to add the candidate weak principles. Recall that some weak principles cite a necessary condition on the justification of some specified suspensions, and others cite a sufficient condition on the justification of some specified suspensions. Recruiting from the last list of seven items yields seven weak principles, each claiming that one kind of item suffices for some specified suspensions to be justified. The same can be done to yield principles which say of the respective items that they are necessary for some specified suspensions to be justified - this yields seven more principles. ${ }^{11}$ In total then we have fourteen kinds of weak principles to put alongside the seven kinds of strong principles that were identified in the previous paragraph.

\subsection{Two Kinds of Suspension-to-Suspension Principles}

I am now going to narrow my focus to strong and weak principles that recruit the first kind of item on our list, namely other justified suspensions. I will call principles of this kind, suspension-to-suspension principles. ${ }^{12}$

11 For a useful discussion of some weak principles that connect beliefs to suspensions, see Rosa (forthcoming).

12 Perhaps the two kinds of weak suspension-to-suspension principles (i.e. one kind that offers a justified suspension that is necessary for a target suspension to be justified, and the other that offers a justified suspension that is sufficient for the same target suspension 
My focus will be even narrower though. This is because suspension-tosuspension principles divide into two different subtypes. One subtype consists in principles that link two suspensions whose contents are logically related, while the other subtype consists in principles that link two suspensions whose contents are not logically related. My focus will be on the first subtype.

Let me briefly illustrate the second subtype, before leaving principles belonging to that type behind. An example of a principle of the second subtype, where the contents are not logically related, is a principle that recruits a justified suspension about the reliability of one's own epistemic faculties. A principle like this arguably plays a central role in the arguments of Descartes's First Meditation. Here is an example of this kind of principle: if a person has a justified suspension about whether the beliefs that are produced by one of her faculties, $f$, are certain, then this confers justification on all of her suspensions that are produced by $f .{ }^{13}$ There is much to be said about principles of this type. I mention them, and offer this example, though, only to illustrate that some suspension-to-suspension principles connect suspensions whose contents are not logically related. My focus in what remains will be on the other subtype, namely principles that connect suspensions whose contents are logically related to one another. I will call these content-connecting suspension principles.

\section{The Importance of Content-Connecting Principles}

Before examining some of the leading content-connecting principles, I want to highlight two reasons why content-connecting principles are especially important in the theory of justified suspension.

One concerns implications for skepticism. Recall the construal of skepticism as covering views, which say, for some domain of claims, that the only justified stance that we can take to any of the claims in such a domain is one of suspension. With this in mind, notice this important point: if it turns out that there are suspension-to-suspension principles of the content-connecting kind, then skepticism will be infectious. This is because if some claim is one for which suspension is the only justified stance, then the correct content-connecting principles will ensure that suspension is the only justified stance to take with respect to some other claim. In this way,

to be justified) can be collapsed into one kind. Though the two kinds of principles have the same form, the justified suspensions that are necessary for some target suspension to be justified could be very different from the justified suspensions that are sufficient for that same suspension to be justified.

13 This principle allows that the recruited suspension confers justification on the target suspensions in a mediated way, by first operating as a justification defeater for the beliefs produced by the relevant faculty, which in turn confers justification on the suspensions produced by that faculty. 
justified suspension will spread. Of course, how justified suspension spreads in this way, from claim to claim, and the extent to which it does so, will depend on exactly which content-connecting principles are correct and on what logical relations hold among the relevant claims. Still the basic point holds: suspension-to-suspension principles of the content-connecting kind can spread justified suspension, both through a domain, and perhaps also to other domains.

On the other hand, if no (or few) content-connecting principles are true, then the skeptic cannot argue from the fact that a subject is justified in suspending about one proposition to the claim that the subject is also justified in suspending about some logically related claim. The skeptic will have to find some other strategy to try to show that the subject is justified in suspending about the second claim, and this will require the skeptic to defend and deploy some other kind of suspension principle.

The second reason it is important to evaluate content-connecting, suspension-to-suspension principles is that doing so will help to reveal the structure of justified suspension. Or, to use some of my earlier language, it will help us to see how justified suspensions hang together. To see this, return to the arena of justified belief. This time consider the debate between foundationalists, coherentists, infinitists, and skeptics over how our justified beliefs hang together. This debate is triggered by the familiar regress argument. That argument, recall, has, as a crucial premise, a belief-tobelief justification principle. This formulation of such a principle will serve our present purposes: if a belief is inferred from some other beliefs, then the inferred belief is justified only if the beliefs that it is inferred from are justified. ${ }^{14} \mathrm{~A}$ principle like this can be repeatedly applied to trigger a regress of justified belief. In turn, that regress forces us to choose one of four views. One, foundationalism, says that the regress terminates with justified beliefs that are not justified by other beliefs. A second, infinitism, says that the regress goes on ad infinitum. A third, coherentism, says that the best way to resolve the regress is to take justification to primarily attach to sets of beliefs, rather than individual beliefs. And a fourth, a form of skepticism, says that the best resolution is to conclude that there are no justified beliefs after all.

If there is a parallel suspension-to-suspension principle that triggers a regress of justified suspensions, then we will have to choose one of four parallel views about how justified suspensions hang together. One, a foundationalist view, says that the regress of justified suspensions terminates with justified suspensions that are not justified by any other suspensions. A second, a form of infinitism, says that the regress of justified suspensions goes on ad infinitum. A third, coherentism about the structure of justified

14 To be defensible, this principle needs to be refined in several ways; such refinements do not, however, take away from my main point here. For some of the needed refinements, see Luzzi (2014). 
suspensions, says that the best way to resolve this regress is to take justification to primarily attach to sets of suspensions, rather than individual suspensions. And, a fourth is a form of skepticism, which says that the best resolution to this regress is to conclude that there are no justified suspensions after all.

Alternatively, if it turns out that all of the suspension-to-suspension principles that could trigger a regress of justified suspensions are false, then we must look elsewhere to determine how justified suspensions hang together. Regardless, any adequate theory of justified suspension needs to tell us how justified suspensions hang together; or it needs to tell us why they don't hang together in any interesting way. I will return to the structure of justified suspensions and the infectiousness of justified suspension as I work through some specific content-connecting, suspension-to-suspension principles.

\section{Five Content-Connecting Principles}

Let's now examine some specific suspension-to-suspension principles of the content-connecting kind. In this section, I will formulate and evaluate five principles of this kind.

\subsection{The Weak and Strong Dual Principles}

I begin with this very plausible principle:

Weak Dual: If S's suspension about $p$ is justified, then S's suspension about not- $p$ is also justified.

Notice that this is a weak principle since it does not say that the justified suspension about $p$ is what confers justification on the suspension about not-p.

This principle is very plausible; there is surely something normatively incoherent about suspending about $p$, while believing, or even disbelieving, not-p. Further support for Weak Dual comes when we consider how this principle comes out on the theories of justified suspension that naturally accompany the four views of suspension that were cataloged earlier. Consider then the main claims that are delivered by orthodox versions of the epistemologies that naturally go along with each of those views of suspension. First, on orthodox epistemologies of sharp credence, the relevant claim is highly plausible. It is this claim: if S's 0.5 credence that $p$ is justified, then S's 0.5 credence that not- $p$ is also justified. Second, on one epistemology of mushy credence, the relevant claim is the following highly plausible claim: if S's maximally mushy credence that $p$ is justified, then S's maximally mushy credence that not- $p$ is also justified. Third, on a plausible epistemology of belief, the key claim that follows from the conjunction of Weak Dual and a sample Higher-Order Belief View is highly plausible, though its logical form 
is complex. It is this claim: if $\mathrm{S}$ has a justified higher-order belief that $n$ (where $n$ is: $\mathrm{S}$ is neither justified in believing $p$ nor justified in believing not- $p$ ), then $S$ 's higher-order belief that not- $n$ is also justified (where not- $n$ is: $S$ is neither justified in believing not- $p$ nor justified in believing $p$ ) - in fact, these are arguably one and the same higher-order belief. ${ }^{15}$ And, last, on at least one plausible epistemology of inquiry, the key claim is also a highly plausible one. It is this claim: if S's inquiry into whether $p$ is true is a reasonable act of inquiry, then her inquiry into whether not-p is true is also a reasonable act of inquiry - in fact, these are arguably one and the same inquiry. Weak Dual, I conclude, enjoys strong support.

What about Weak Dual's strong counterpart? That is this principle:

Strong Dual: If S's suspension about $p$ is justified, then this confers justification on S's suspension about not-p.

This principle is far less plausible. One problem it faces is a symmetry problem. It is highly plausible that the relation of conferring justification is asymmetric ${ }^{16}$; but there does not seem to be any epistemic asymmetry between suspensions about $p$ and suspensions about not- $p$, which would give one of these the needed priority over the other, so that the one always confers justification on the other, but the second never confers justification on the first. There is more to be said here about Strong Dual, but this is a serious strike against it.

Even if Strong Dual is true though, not much follows about either of the two issues highlighted in the previous section. The skeptic will not get far by using either Strong Dual or Weak Dual since these principles only allow justified suspension to spread from a person's required stance regarding $p$ to her stance regarding not-p. As for the structure of justified suspension, the most these principles imply is that justified suspensions about contradictory propositions will either both be justified or both be unjustified. This, however, tells us nothing about the structure of any other sets of justified suspensions besides those that are directed at contradictories. So neither dual principle can help us decide among the four structural options that were

15 Notice that the only possible difference between these two beliefs lies in the order of the disjuncts in the negated disjunctions that are the contents of the respective higher-order beliefs. The logical form of the content of the first belief is $\sim(\mathrm{JB} p \vee \mathrm{JB} \sim p)$, and the logical form of the content of the second is $\sim(\mathrm{JB} \sim p \vee \mathrm{JB} p)$.

16 Someone might resist the claim that conferring justification is an asymmetric relation by claiming that coherentist theories of justification provide us with models of beliefs that mutually confer justification on one another. Two points in response. First, plausible coherentist theories do not say that two beliefs in logically equivalent propositions can confer justification on one another - such a view would be much too permissive. Plus coherentists typically hold that much larger sets of beliefs need to be in place for there to be any justified beliefs. And, second, on the best formulations of coherentism, justification primarily attaches to groups of beliefs, not individual beliefs - so one individual belief never confers justification on another individual belief. 
outlined earlier. ${ }^{17}$ However, the fact that justified suspensions are paired in this way is compatible with the view that either the justification enjoyed by the suspension about $p$ or the justification enjoyed by the suspension about not- $p$ has its justification conferred on it by something outside this pair of suspensions. And the operative principle that governs that conferring might be some other strong suspension-to-suspension principle; moreover, that principle might trigger a regress of justified suspensions. Let's examine some principles that might do this.

\subsection{The Closure and Transmission Principles}

Next are some principles that are modeled on some familiar belief-tobelief principles. Two are counterparts of one another. The weak principle in the pair is modeled on the familiar idea that justified belief is closed under known entailment. We can work with this rendering of that idea, a singlepremise closure principle, which says:

Closure for Belief: If (i) S's belief that $p$ is justified, (ii) S competently deduces $q$ from $p$, and (iii) $S$ thereby comes to believe $q$ while retaining her justified belief that $p$ throughout, then S's belief that $q$ is justified. ${ }^{18}$

Here is the parallel principle for suspension:

Closure for Suspension: If (i) S's suspension about $p$ is justified, (ii) $S$ competently deduces $q$ from $p$, and (iii) $S$ thereby comes to suspend about $q$ while retaining her justified suspension about $p$ throughout, then S's suspension about $q$ is justified.

To see the strong counterparts of these principle, return to belief. There Closure for Belief has as its strong counterpart the so-called "transmission principle", which adds to Closure for Belief the claim that it also follows from

17 There are other candidate suspension-to-suspension principles, besides Weak Dual and Strong Dual, that have no weighty consequences for skepticism's prospects or for revealing the structure of justified suspensions because they can't (even if true) spread justified suspension across claims in some significant way. Other examples include principles modelled on disjunction introduction (e.g. if S's suspension about $p$ is justified, then S's suspension about $p$ or $q$ is justified), principles modelled on conjunction introduction (e.g. if S's suspension about $p$ is justified and S's suspension about $q$ is justified, then S's suspension about $p$ \& $q$ is justified), and principles modeled on reasoning across a known biconditional (e.g. that if $\mathrm{S}$ has a justified suspension about $p$, and $\mathrm{S}$ knows that $p$ iff $q$, then S's suspension about $q$ is also justified). Notice that the claim that these principles do not carry weighty consequences for skepticism or for the structure of justified suspensions is about what these principles imply; it is not a claim about whether they are true. See Rosa (forthcoming) for arguments against simple versions of these principles.

18 Read 'competently deduces' as a success term that implies knowledge; so $S$ competently deduces $q$ from $p$ entails that $S$ knows that $p$ entails $q$. My formulation here is closely modeled on Hawthorne's Single-Premise Closure principle for knowledge in his (2004). 
the antecedent of Closure for Belief that it is the satisfaction of (i)-(iii) that confers justification on S's belief that $q$. Here is a version of that principle:

Transmission for Belief: If (i) S's belief that $p$ is justified, (ii) $S$ competently deduces $q$ from $p$, and (iii) $S$ thereby comes to believe $q$ while retaining her justified belief that $p$ throughout, then (i)-(iii) confer justification on S's belief that $q$.

And here is the parallel principle for suspension:

Transmission for Suspension: If (i) S's suspension about $p$ is justified, (ii) $\mathrm{S}$ competently deduces $q$ from $p$, and (iii) $\mathrm{S}$ thereby comes to suspend about $q$ while retaining her justified suspension about $p$ throughout, then (i)-(iii) confer justification on S's suspension about $q$.

Because Transmission for Suspension is stronger than Closure for Suspension, if Closure for Suspension is false, then Transmission for Suspension is also false. I will now argue that Closure for Suspension is false.

Consider a coin that is about to be flipped, and a subject who has a justified suspension about whether the coin will land heads. Suppose that our subject knows that the coin will land heads entails propositions like coins exist, coins will be flipped, and coins either land heads or tails. Suppose also that she competently reasons from the claim that the coin will land heads to one of these last claims, and that while doing so she retains her suspension about whether the coin will land heads. Closure for Suspension implies that she is justified in suspending about coins exist, coins will be flipped, and coins land either heads or tails. But this is clearly false.

The implausibility of Closure for Suspension is obvious when the point is put in terms of sufficient conditions. Here it is helpful to think in terms of a sufficient condition, $s$, on the truth of a proposition, $p$. Thought of in terms of necessary and sufficient conditions, Closure for Suspension says that if someone has a justified suspension about whether some sufficient condition, $s$, for the truth of $p$ has been satisfied, then she is justified in suspending about $p$. This is clearly false though. Having this kind of justified suspension does not preclude a subject from having a justified belief (or knowledge) that another sufficient condition for $p$ is met. Since the latter will put her in an excellent position to have a justified belief that $p$ (or even to know $p$ ), it precludes her from being justified in suspending about $p .{ }^{19}$

This is confirmed when we run this last point through the four views of suspension. First, The Sharp Credence View allows that one can have a justified 0.5 credence that $s$, and yet not be justified in having a 0.5 credence that $p$, all while knowing that $s$ entails $p$. This will happen when one has a sufficiently high justified credence that some other sufficient condition on the

19 Here, and elsewhere, I assume the following weak uniqueness principle: if $S$ is justified in believing $p$, then $\mathrm{S}$ is not justified in suspending about $p$. 
truth of $p$ is satisfied. Similarly, The Maximally Mushy Credence View allows that one can have a justified maximally mushy credence about $s$, yet not be justified in having a maximally mushy credence about $p$, all while knowing that $s$ entails $p$. This will happen when one has a sufficiently high justified credence that some other sufficient condition on the truth of $p$ is satisfied. The same is true on Higher-Order Belief Views. Here one can have a (higherorder) justified belief that one is neither justified in believing, nor justified in disbelieving, $s$, yet not be justified in believing (at the higher-order) that one is neither justified in believing $p$ nor justified in disbelieving $p$, again all while knowing that $s$ entails $p$. This will happen when one is justified in believing that some other sufficient condition on $p$ is satisfied. And, last, The Inquiry View of suspended judgment allows that it can be reasonable for one to inquire into whether $s$ is true, yet it not be reasonable for one to inquire into whether $p$ is true, again, while also knowing that s entails $p$. All three of these things are true when one knows that some other sufficient condition on the truth of $p$ is satisfied. This last piece of knowledge makes it unreasonable to inquire into whether $p$ is true or false. ${ }^{20}$ This review of the four leading views of the nature of suspension provides additional support against Closure for Suspension.

\subsection{Excursus: Can Suspensions Figure Into Inferential Reasoning?}

It is worth pausing at this point to consider an important issue that bears on Closure for Suspension, Transmission for Suspension, and another principle that I will soon examine. The issue concerns a potentially problematic assumption that might underlie these principles. The concern is that these principles assume that suspensions can figure into inferential reasoning, as beliefs do. But it is far from clear what is involved in, say, reasoning and inferring to a conclusion, about which one suspends judgment.

The issue of whether suspensions can figure into inferential reasoning is important and underexplored. But it is an issue that can only be adequately answered with a much different, and longer, paper. More importantly, since it concerns the non-normative nature of suspensions, rather than the normative nature of suspensions, I am going to set it aside. Still, two points are worth keeping in mind. The first is that it is not clear that Closure for Suspension and Transmission for Suspension really do require that suspensions figure into inferential reasoning. There are two reasons for this. One is that competently deducing $q$ from $p$ does not require either suspending about $q$ or suspending about $p$ - keep in mind that it is propositions, not attitudes towards propositions, that are deduced from one another. Second, thereby coming to suspend about $q$ can occur as the last in a series of mental states without that series constituting an episode of inferential reasoning. In fact,

20 For defense of this claim, see Friedman (2017). 
suspensions might show up as both the first and last items in such a series and yet that series not be an episode of inferential reasoning. This is so with belief: a series of mental states can begin with one belief and end with another belief, and yet that series not constitute an episode of inferential reasoning. For example, on some models of higher-order belief, a person can begin with the belief that grass is green, then go into some self-monitoring mental states, and then form the higher-order belief that she believes that grass is green and yet no inferential reasoning needs to have occurred during this time. ${ }^{21}$ Similarly, suspensions might figure into a series of mental states, perhaps one that also includes deducing one proposition from another, even if that series does not constitute an episode of inferential reasoning.

Second, it is worth going back over the views about the nature of suspension canvassed in Section 1, and asking whether they allow for suspensions to figure into inferential reasoning. When we do this, we find that on Higher-Order Belief Views, there is no problem with suspensions figuring into inferential reasoning, since suspensions are themselves just beliefs (and surely beliefs can figure into inferential reasoning). As for The Sharp Credence View and The Maximally Mushy Credence View, we can at least say that proponents of these views should be motivated to model suspensions so that they can figure into inferential reasoning since this is just an instance of the more general ambition of modelling credences so that they can figure into inferential reasoning. It would be a serious cost to theorizing with degrees of belief (whether sharp or mushy), if degrees of belief cannot figure into our inferential reasoning. ${ }^{22}$ Things are admittedly different with The Inquiry View. Here it seems much less obvious that suspensions can figure into inferential reasoning, since, according to this view, suspensions are directed at questions, not propositions. There might however be some non-obvious way to show that questions can figure into inferential reasoning.

Let's return to the normative nature of suspensions and look at one last content-connecting suspension-to-suspension principle.

\subsection{The Counter-Closure Principle}

The last point I argued for before the excursus concerned justified suspensions about known sufficient conditions. The point was this: having a justified suspension about some sufficient condition for the truth of a proposition does not entail being justified in suspending about that proposition. This is because one can have a justified belief (or know) that some other sufficient condition on the truth of that proposition is satisfied when this is so, one is justified in believing that proposition, and one is not justified in suspending about it.

21 In such cases one belief is non-inferentially based on another belief.

22 For a partial defense of the view that credences can figure into inferential reasoning, see Staffel (2013). 
What about having a justified suspension about whether a necessary condition on the truth of a proposition is met? This is equivalent to the question of whether a principle that I will call Counter-Closure for Suspension is true. To see what this principle is, consider first this version of the CounterClosure principle for justified belief:

Counter-Closure for Belief: If (i) S has a justified belief that $q$ (ii) that is solely based on a competent inference from $p$ to $q$, and (iii) $\mathrm{S}$ believes that $p$, then S's belief that $p$ is justified. ${ }^{23}$

Here is the parallel principle for suspension:

Counter-Closure for Suspension: If $S$ has a justified suspension about $q$, (ii) S competently infers $q$ from $p$, and (iii) S suspends about $p$, then S's suspension about $p$ is justified. ${ }^{24}$

This principle is a weak one since it does not say that the justified suspension about $q$ confers justification on the suspension about $p$.

Counter-Closure for Suspension is the best candidate for a principle that can trigger a regress of justified suspensions. For, if this principle is true, then each proposition that is known to entail a proposition about which one is justified in suspending will itself be a proposition about which one is justified in suspending. Counter-Closure for Suspension could then iterate, and thereby spread justified suspension further back through entailing propositions, thus triggering a regress of justified suspensions. Of course, if Counter-Closure for Suspension is false, then it won't trigger any such regress and will therefore not shed any light on the structure of justified suspensions.

Initially Counter-Closure for Suspension might seem plausible. For example, I know that a necessary condition on a coin having landed heads is that the coin was flipped. But if I have a justified suspension about whether the coin was flipped, then surely I am also justified in suspending about whether it landed heads. Despite this, however, the principle is false. The reason is simple: in addition to having a justified suspension about whether a necessary condition for $p$ is met, one might have a justified belief (or knowledge) that some other necessary condition for $p$ is not met. When this happens, one is not justified in suspending about $p$ - instead one is justified in believing that $p$ is false.

This too is confirmed by each of the four views of suspension. Here, in somewhat compressed form, are the crucial points. First, The Sharp Credence

23 This formulation is fine for present purposes. Again, for some of the needed refinements, see Luzzi (2014).

24 Notice that no reference is made in this principle to any inferential reasoning that involves a transition from one suspension to another suspension, and thus reflects the thought from the last section that perhaps no inferential reasoning needs to figure into any content-connecting suspension-to-suspension principles. 
View allows that one can have a justified 0.5 credence that $n$, a justified 0.5 credence that not- $n$, know that $p$ entails $n$, and yet not be justified in having a 0.5 credence that $p$. All of this will be true if one has a sufficiently high justified credence that some other necessary condition on the truth of $p$ is not satisfied. Similarly, The Maximally Mushy Credence View allows that one can have a justified maximally mushy credence that $n$, know that $p$ entails $n$, yet not be justified in having a maximally mushy credence that $p$. This will happen when one has a sufficiently high justified credence that some other necessary condition on the truth of $p$ is not met. The same pattern holds on Higher-Order Belief Views. One can have a higher-order justified belief that one is neither justified in believing, nor justified in disbelieving, $n$, know that $p$ entails $n$, and yet not be justified in having a higher-order belief that one is neither justified in believing, nor justified in disbelieving, $p$. Once again this will happen when one is justified in believing that some other necessary condition on $p$ is not satisfied. Last is The Inquiry View. This view allows for cases in which it is reasonable for one to inquire into whether $n$ is true, when one knows that $p$ entails $q$, and yet it is unreasonable for one to inquire into whether $p$ is true. All of this will hold when one knows that some other necessary condition on the truth of $p$ is not satisfied. This last piece of knowledge makes it unreasonable to inquire into whether $p$ is true or false. This induction across the four views is more support for rejecting Counter-Closure for Suspension.

\section{Lessons}

Where does all of this leave us? In particular, what lessons can we now draw about the skeptic's prospects and about the structure of justified suspensions?

Take the skeptic's prospects first. Since we have, at the very most, only identified two suspension-to-suspension principles that are true (namely Weak Dual and Strong Dual), and since those two principles can do very little to spread justified suspension across a body of claims, the skeptic's prospects look a little dimmer. Principles like Closure for Suspension, Transmission for Suspension, or Counter-Closure are not available to show that justified suspension is infectious, since those three principles are false.

What about the structure of justified suspension? Based on the finding that Counter-Closure for Suspension is false, we can at least say this much: a regress of justified suspensions is not triggered in the same way that a regress of justified beliefs is typically thought to be triggered. Since it is unclear how else a regress of justified suspensions could be triggered, it remains unclear how justified suspensions might hang together. Much more work needs to be done to reveal the structure of justified suspensions. ${ }^{25}$

25 Perhaps because the approach that borrows from the theory of justified belief has not yielded anything, an entirely different approach is needed to reveal the structure of justified suspension. 
I end with a third lesson. It is based on the kinds of considerations and the cogency of the considerations that I offered against Closure for Suspension, Transmission for Suspension, and Counter-Closure for Suspension. Those considerations, both in kind and in cogency, are very different from the familiar considerations that are offered against the parallel principles for justified belief. Epistemologists on both sides of the debates about Closure for Belief, Transmission for Belief, and Counter-Closure for Belief will, I think, agree that there are no simple, highly cogent considerations about the epistemology of necessary and sufficient conditions that can be offered against any of these three principles. Debates about those principles continue because there are no simple highly cogent arguments on either side of the debate. As we have seen though things are quite different for the parallel principles governing suspension: each of those principles has been definitively shown to be false, both on general grounds about the epistemology of necessary and sufficient conditions, and on the basis of the inductions across the four leading views about the nature of suspension. The difference in both the kinds and cogency of the considerations that bear on the parallel principles in the realms of suspension and belief is some reason to think that theorizing about justified suspension can unfold very differently from how theorizing about justified belief unfolds. This, I submit, gives us even more reason to continue to theorize about justified suspended judgment.

\section{Acknowledgments}

For helpful remarks on a much earlier version of this paper, thanks to my commentator, Baron Reed, and the audience at the 2018 Central Division Meetings of the American Philosophical Association. Thanks also to Adam Sanders and an anonymous referee for this journal.

\section{References}

Archer, A. (2018). Wondering What You Know. Analysis 78: 596-604.

Archer, A. (2019). Agnosticism, Inquiry, and Unanswerable Questions. Disputatio 11: 63-88.

Friedman, J. (2013a). Suspended Judgment. Philosophical Studies 162: 165-181.

Friedman, J. (2013b). Rational Agnosticism and Degrees of Belief. Oxford Studies in Epistemology 4: 57-81.

Friedman, J. (2017). Why Suspend Judging? Nous 51: 302-326.

Hawthorne, J. (2004). Knowledge and Lotteries. New York: Oxford University Press. 
Luzzi, F. (2014). What Does Knowledge-Yielding Deduction Require of Its Premises? Episteme 11: 261-275.

Raleigh, T. (forthcoming). Suspending is Believing. Synthese.

Rosa, L. (2019). Logical Principles of Agnosticism. Erkenntnis 84: 1263-83.

Rosenkranz, S. (2007). Agnosticism as a Third Stance. Mind 116: 55-104.

Staffel, J. (2013). Can There Be Reasoning With Degrees of Belief? Synthese 190: 3535-3551.

Sturgeon, S. (2010). Confidence and Coarse-Grained Attitudes. Oxford Studies in Epistemology 3: 126-149.

White, R. (2010). Evidential Symmetry and Mushy Credence. Oxford Studies in Epistemology 3: 161-186. 